\title{
Transactional distance in a blended learning environment
}

\author{
Jon Dron ${ }^{\star}, \mathrm{a}$, Catharine Seidel ${ }^{\mathrm{b}} \&$ Gabrielle Litten $^{\mathrm{b}}$ \\ ${ }^{\mathrm{a}}$ University of Brighton, $U K ;{ }^{\mathrm{b}}$ Crawley College, UK
}

This paper presents a case study that describes and discusses the problems encountered during the design and implementation of a blended learning course, largely taught online through a web-based learning environment. Based on Moore's theory of transactional distance, the course was explicitly designed to have dialogue at its heart. However, the reality of systemic behaviours caused by delivering such a course within a group of conventional further and higher educational institutions has led to an entirely unanticipated reversion to structure, with unpleasant consequences for both quality and quantity of dialogue. The paper looks at some of the reasons for this drift, and suggests that some of the disappointing results (in particular in terms of the quality of the students' experience and associated poor retention) can be attributed to the lack of dialogue, and consequent increase in transactional distance. It concludes with a description and evaluation of steps currently being taken to correct this behaviour.

\section{Introduction}

This paper describes a blended learning course which has attempted to apply Michael Moore's theory of transactional distance. This theory asserts that it is transactional rather than physical distance which is of greatest significance in any educational transaction (Moore \& Kearsley, 1996). Transactional distance is measured on a continuum of structure and dialogue. The more structure, the less dialogue and vice versa (Figure 1). A highly structured course will give little opportunity to challenge concepts and explore congruent or tangential paths, while dialogue will inevitably lead to departures from planned outcomes and result in new, unanticipated learning outcomes.

\footnotetext{
^Corresponding author. School of Computing, Mathematical and Information Sciences, University of Brighton, Watts Building, Lewes Road, Brighton BN2 4GJ, UK. Email: jon.dron@brighton.ac.uk
} 


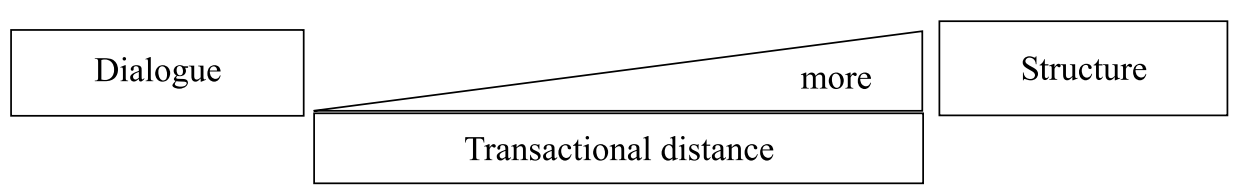

Figure 1. Relationship between dialogue and structure

Moore does not suggest that either structure or dialogue is an inherently good thing. Each may be appropriate in different circumstances and a typical educational event such as a conventional lecture will, at a micro-level, move constantly between the two. However, the reciprocal relationship between them at any given point is immutable. A third dimension of the theory suggests that more autonomous learners, being self-directed, are better able to cope with more structure while less autonomous learners benefit more from greater dialogue. Moore equates less autonomy with more teacher control. Experimental evidence (Saba \& Shearer, 1994) based on predictions of a system dynamics model correlated with discourse analysis, appears to confirm that the theory is substantially correct. However, there may be some grounds for believing that there are rare exceptions (Dron, 2004) and there is a fuzziness in his formulation that allows for different interpretations depending on whether transactional distance is considered as a two by two matrix, a single continuum or distinct clusters (Garrison, 2000). In this paper we interpret structure and dialogue as broadly characterising two extremes of a single continuum with a reciprocal relationship between the two.

\section{Beginnings}

In 2000, HEFCE (the Higher Education Funding Council for England) announced that it would fund a number of pilot projects to create Foundation Degrees. Foundation Degrees are strongly work-based or work-related, designed and managed in collaboration with employers and delivered mainly by Further Education (FE) colleges. Equating to the first two years of an honours degree, they target students who might otherwise be excluded from higher education, notably those with unconventional qualifications and/or in work. Their focus tends to be more practical than academic.

Led by the University of Brighton, a consortium consisting of two universities, four FE colleges and various employers submitted a successful bid for HEFCE funding which led, in 2001, to the development of the eSystems Design \& Technology degree. The course was designed as an Internet Computing degree, to be delivered solely as a part-time, four-year course. For strategic reasons the plan was to deliver at least some of the course electronically, though the exact amount of and mechanism for this delivery was not made explicit.

A Course Development Team (CDT), consisting of representatives from each college and a University-based development leader, was appointed and given 
responsibility for course development, with quality control provided by the University. A course leader from the University was appointed with a research background in and practical experience of online collaborative learning. However, though playing a significant part in strategic planning, other commitments prevented the appointee (the first author of this paper) from playing more than a strategic role in course development.

\section{Defining the course ethos}

Decisions about the form of the course were made, grounded in theory and pragmatic choice. Pragmatically, the Internet was proposed as the main delivery mechanism so that students could access course materials from their workplace or from home. This was also seen as an effective means of monitoring and controlling the content and quality of the course across multiple colleges.

Lack of time and resources militated against the development of highly structured course materials. As the course was aiming to attract learners who were unwilling or unable to enter conventional higher education, there was a need to cater for a rich variety of prior knowledge and learning styles. Wedermeyer (1971) noted that independent study of the early 1970s typically offered little freedom in goal determination and activity selection, an issue that has arisen frequently since then despite the ubiquity of computer-mediated forms of distance education. The need to cater for multiple learning styles implied alternative perspectives on the resources, multiple resources catering for different needs or an adaptive hypermedia approach (Brusilovsky, 2001). Furthermore, to cater sufficiently for a variety of learning styles it was felt important to make use of rich media which, as Laurillard observes are generally too expensive to be produced by individuals (Laurillard, 1993, p. 182). However, with little time to develop such resources, these approaches were not deemed possible.

Applying transactional distance theory, it was decided to define an ethos based on learning through dialogue. A dialogue-based approach would require a lower commitment of development time, albeit at the expense of time spent maintaining dialogue when the course was running (Figure 2). Most discussions would be facilitated through online asynchronous forums. Synchronous approaches were felt to provide insufficient flexibility for students in full time work, as well as posing some technical obstacles.

The course was designed to be delivered in a blended mode. Seely Brown and Duguid observe that 'digital technologies are adept at maintaining communities already formed. They are less good at making them'. (Seely Brown \& Duguid, 2000, p. 206). For this reason, online discussions would be supplemented by occasional face-to-face meetings. They would also support the few parts of the course that required specialised laboratory facilities, which were kept to a minimum by basing practical work primarily on free and open source software.

Using computer mediated communication is a potentially hazardous approach as mediated communication is in some ways a pale shadow of face-to-face discussion 


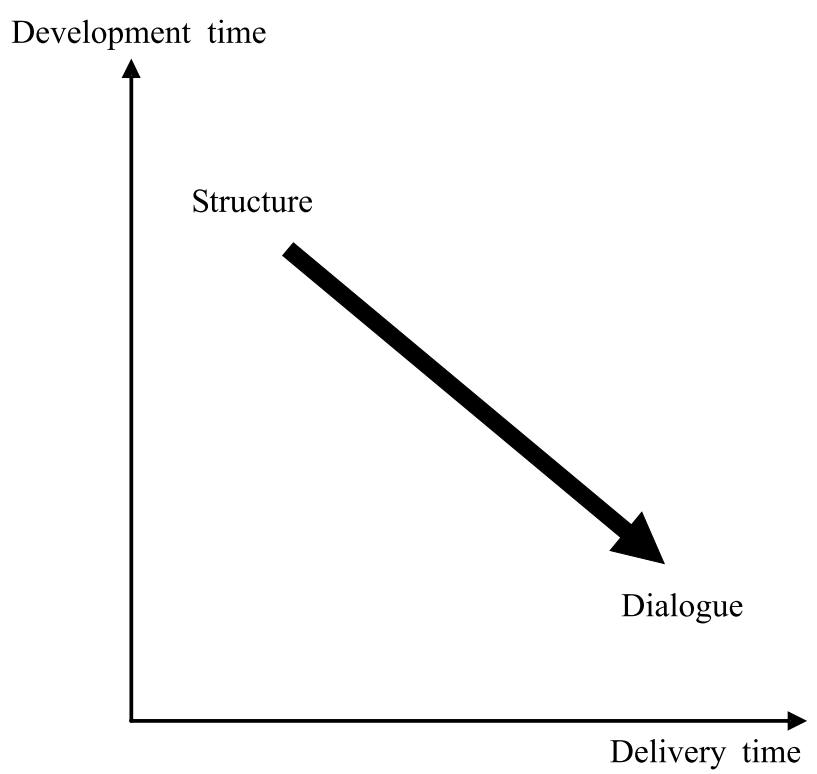

Figure 2. Relationship of delivery to development time for structured/dialogic delivery modes

and is not a simple replication of such discourse (Peters, 2000). Given the need to develop a learning community, course developers were urged to employ Salmon's five step model (Salmon, 2000) and were given training in the approach. Salmon outlines the five stages through which she believes an online learning community must pass in order to reach the stage at which learners are constructing knowledge through interaction-access \& motivation, online socialization, information exchange, knowledge construction and finally, development. The model was adopted to provide teachers new to delivering distance learning with a reassuring and effective framework to assist them in coming to terms with this unfamiliar mode of teaching.

With an explicit social constructivist ethos (Vygotsky, 1978), it was hoped that, with time and suitable models of good practice, much of the learning might be facilitated by the students themselves. Because students would come from relevant work backgrounds and (by virtue of enrolling on such a course) were expected to be mature, motivated learners, it was hoped that they might have much to offer in terms of experience and knowledge and form an effective community of practice. As Wenger puts it, 'The value of an institutionalized setting for learning often resides as much in its community-building potential as in the pedagogical intentions of its curriculum' (Wenger, 1998, p. 208).

Many authors have emphasized the importance of performance evaluation in education (Bruner, 1966; Gagne, 1985; Laurillard, 1993). Summative and formative assessment would be embedded throughout the course with a wide variety of approaches including portfolios, programming exercises, online tests, examinations, vivas, reports and problem-based assignments, in the belief that this would help 
maintain focus and motivation. The result of this was that students would seldom spend more than three weeks without the need to submit some form of assessed work. Although efforts were made to make much of this assessment as authentic as possible, in particular by relating it to the students' workplace, the course leader had some misgivings about the reliance on assessment to provide extrinsic motivation (Whitehead, 1929; Illich, 1971; Holt, 1977).

\section{Preparing for delivery}

The CDT met face-to-face approximately monthly, using an asynchronous discussion forum to facilitate the shared development of module specifications between meetings. This small group were able to engender a strong sense of shared responsibility and identity, which it was hoped would be replicated amongst student groups once the course was running.

Once the course outline had been approved and module specifications agreed, tutors from each of the four participating FE colleges were appointed to develop and to deliver the course. Only two of the 20 or so tutors involved in preparation of the first year's modules had any experience of distance learning, let alone online delivery, and only a handful had been involved in course development prior to this. Most were excited by the challenge though a small but significant minority expressed scepticism about the wisdom of choosing this method of delivery, preferring a traditional faceto-face approach. All tutors were required to attend an online tutor training (OTT) course created by one of the more experienced online tutors, based heavily on Salmon's five step model of e-moderating (Salmon, 2000).

An e-learning expert was employed to facilitate workshops in which module outlines were prepared and development work shared amongst the teaching team. This helped to encourage a strong sense of ownership of the modules by their development teams. These sessions had a strong emphasis on developing module structures and associated static materials, with, perhaps, insufficient emphasis on dialogue. For many tutors this was their first encounter with the course and its approach, so these workshops influenced them strongly.

The CDT believed that they had anticipated some of the potential pitfalls of online education, but it soon became evident that this was not so. The huge change in teaching approach required and the cascade of systemic dependencies that it would set in motion is the main topic for the rest of this paper.

\section{The first two years}

Twenty-eight students enrolled at the start of the first year. To compound this disappointing start, one college recruited only three students, one of whom dropped out almost immediately followed by a second a few months later. Within a couple of months of starting, two of the colleges had amalgamated, with consequent upheavals and uncertainties for staff and students alike. 
In the rush to prepare for the start of the course, it went almost unnoticed that a small number of tutors had failed to attend the OTT course and that, of those who had, only about half had successfully completed it by the time the course began. The main reason given was the lack of time, but the consequent lack of experience of dialogue-based learning proved problematic later.

A poor student retention rate was matched by a high turnover rate for staff. Although another instance of the OTT course was run, this failed to keep pace with the rapid staff turnover which in turn meant that the already over-stretched staff were even less prepared for the processes of online teaching. To make matters worse, new tutors lacked the sense of ownership of the process that motivated the founding team.

\section{Running the course: the tutor experience}

It became apparent early in the first year of the course that most tutors were relying on familiar teaching methods and using the discussion boards only as an occasional means of communication with the students. Despite extensive online and offline encouragement this reliance on structure rather than dialogue did not improve throughout the first two years of the course.

FE college tutors' very full timetables contained discrete blocks of time when teaching was supposed to occur for this course (typically a single block of three hours each week, a mere thirteen percent of an average FE lecturer's teaching time), militating heavily against its asynchronous delivery

Given that virtually all the students on the course are working, by far the majority of their study and communication occurred in the evenings or at weekends. Although most tutors adapted to this pattern of working, it fitted very uneasily with the rest of their over-filled timetables and their expectations that evenings and weekends should be free from the demands of student contact.

Tutors found that dialogue-led delivery often took much longer than they had anticipated. To save time it was often simpler to rely on more traditional methods including a tendency to put off solving students' problems until the scheduled faceto-face session. This was exacerbated by the fact that many of the early course modules involved the acquisition of specific skills and information (programming, database design, simple Internet technologies and concepts). These topics were often perceived as lending themselves more readily to a structured one-way mode of delivery. Communication was confined to clarifying misconceptions and discussing good practice, tending to be directive rather than discursive.

\section{Running the course: the student experience}

The reason most often given for dropping out was and is students' inability to cope with the demands of their work and the course. However, it soon became clear that some of their preconceptions about the course and their own learning processes were at odds with the course ethos. Only a few were regular contributors to discussions, with many content to simply log in, do the set reading/tasks and log out again without 
any dialogue. The large amount of assessment spread throughout the course was over-demanding and demoralizing for many students. Those hard-pressed for time got on with the essential reading and the assignments, and omitted the unassessed, and therefore apparently unnecessary dialogue.

Although some students were willing to help each other out with corrections to coding, good explanations and resource sharing, others saw helping each other as a diversion from their own studies, failing to appreciate the benefits that can ensue from teamwork and dialogue. Some students lacked confidence, and so avoided posting questions or problems to the discussion forums, for fear of ridicule.

Perhaps because of their perceptions of education, combined with the demands of their employers, many students valued the acquisition of skills and factual information more highly than the surrounding processes of learning that can turn it into useful knowledge.

Lack of timely feedback discouraged students from using the medium. One student summed it up well:

\footnotetext{
We do need more feedback to discussions and problems posted to the teamroom. Some tutors are very good at this but others seem only to drop in once a week-and a week is a long time on this course! Several students feel that, whatever the value of the classroom contact, it should be possible to do the course entirely remotely.
}

The compound effect of all these factors was that in most modules, only staccato discourse occurred, rarely stepping higher than Salmon's third stage of Information Exchange (Salmon, 2000).

\section{A vicious circle}

One tutor complained, 'I have tried without much success to get students to have discussions in the teamroom. One or two students may join in, but no one else doesyou can end up having a discussion with yourself.' A student expressed the view, 'teamroom activity breeds teamroom activity, and lethargy breeds lethargy.'

A vicious circle developed. A predominance of skills-based learning combined with tutors' reticence to encourage dialogue online meant that the discussion areas were under-utilized. The fewer expectations placed on the students, the less they felt the need to contribute.

At this point, Moore's theory of transactional distance became very apparent. As dialogue diminished, structure came to dominate. Students, insufficiently supported by a learning community, came to rely increasingly on course notes. The more structured the course became, the fewer the opportunities for dialogue arose. The effects of this on less autonomous learners were devastating.

Few of the students had acquired the skill to be autonomous learners in an academic setting. The fact that most had responsible jobs in 'white water' environments (Vaill, 1996, p. 4), where change is the norm and learning must be a way of life was not considered. For better or worse the course was built around a traditional academic framework, so students needed help and guidance to explore issues and 
clarify concepts. In the absence of an effective discussion forum, the brief face-to-face meetings, originally intended mainly to provide social cohesion, increasingly became the main occasions for learning on the course. One student noted:

Lessons are great, covering points missed and checking everything is as it should be, but as everyone seems to realize team room could be used more for discussion and covering points.

Torn between the demands of work and the need to participate in these contact sessions, with inadequate structured resources and no community to turn to in between, many students became disillusioned, and demotivated. By the end of the first year, half of the students had left the course and the college with a single remaining student left the programme.

With only two FE colleges now involved in delivery, the second year began. Although recruitment was a little lower than that of the first year, slightly better retention rates reflected refinements in delivery and design, especially a slight reduction in the assessment load. However, it was apparent that the course was still plagued by systemic problems, driven both by the tutors and the students.

\section{Away from structure, returning to dialogue}

Senge argues that, in any system, structure is a key determinant of behaviour (Senge, 1993, pp. 40-41). The central problems of the course have been observed to be structural in nature, leading to systemic behaviours which hinged around a number of inter-related issues. These in turn led to a cycle of ever-decreasing returns, excessive workloads and a relative paucity of rich interactions in the virtual space. It was felt necessary to break that cycle. It was not possible to radically improve the allocation of time to tutors, and it was impractical to consider a major change in the surrounding educational environment and timetabling. There was still no time to develop effective structured learning materials. However, increasing dialogue seemed an achievable target.

In collaboration with tutors, a simple 'chunk and talk' strategy was developed. Students would be presented with a discussion forum as the entry point to each module, in which the tutor would outline the tasks for the week (or chunk of several weeks) and initiate a dialogue. By starting with a discussion, it was hoped that students would focus much more on process rather than absorption of content, and that there would be more of an emphasis on the learning community, reducing isolation for the learners.

Chunking topics into logical units provided students with more control over their own work patterns, although this was counterbalanced somewhat by the demands of dialogue, participation in which required continual attention.

To help build a more dynamic learning community (and also because of the declining group sizes), the online teaching for both colleges was amalgamated, with a single tutor responsible for leading the online discussion for each chunk of learning. Faceto-face meetings would, however, still be led at each college by the local staff member. 
It was hoped that this would engender more collaboration amongst the teaching team, and that as staff gained a greater understanding of the importance of online communication and collaboration, they would find it easier to facilitate the development of this sense of partnership amongst the student community.

To help assist tutors lost within an unfamiliar online environment, strong advice was given to module designers to follow a pedagogy based on Kolb's experiential learning cycle (Kolb, 1984). This cycle of abstract conceptualization, reflective observation, active experimentation and concrete experience, with its focus on situated learning, was seen to fit neatly with the work-related/work-based nature of the course as well as providing a simple framework and easy-to-follow formula.

Summative assessment would be significantly reduced and what was left would be embedded further into the practice of the course. Specifically, some assignments required participation in online discussions, for example in designing the solution to a problem or exploring recent technological developments

\section{Some early results}

The new approach has been implemented for one semester to the current cohort of 10-12 students per year group. Modules that are running for the first time have been developed on the basis of this approach, while existing modules have been adapted to a greater or lesser extent.

The results have not all been encouraging. Staff changes and the limitations imposed in the hard-pressed FE sector have again resulted in insufficient time being allowed to do the approach full justice and not all staff have taken the advice to use the Kolb cycle as a framework. Similarly, although there is general recognition of the need for discussion, several tutors continue to use forums to ask simple, answerable questions rather than exploring the problems and issues that allow learners to explore concepts and engage in dialogue.

Just over $60 \%$ of all accesses to the system over the past semester were in the communication areas. Analysis suggests a roughly similar proportion in previous years $(60 \%$ discussion for the first year the course ran, $57 \%$ for the second) which, given potential inaccuracies and the fact that the systems in use are not directly comparable, is disappointing. However, the use of communication areas varies with year group, with rates of $64 \%$ for first year students, $61 \%$ for second year students and $57 \%$ for third year students.

There are still very few deep conversations going on, with the majority of messages concerned with either problem solving or the process, such as giving assignment dates and schedules. Worse, although it is difficult to draw direct comparisons due to the different organization of the sites, there seems little difference in the actual number of messages posted when compared with previous years.

One positive outcome has been observed. This year, the most active students have posted around three times as many messages as the least active, whereas last year the ratio was greater than eighteen to one. This broadening of participation in dialogue 
will lead to a greater awareness of the presence of others, hence reducing the loneliness and isolation that less active participants experienced before.

Retention rates have improved when compared with the same period in previous years. Discussion forums are not the only reason for this: contributory factors include a more thorough and honest interview process, a reduction in assessment load, greater experience of tutors, a more reliable online environment, more diverse discussion groups, better pedagogy and reduced dependence on tutorprepared materials.

The move to a more discussion-oriented process has not been universally popular with our first cohort of students, now in their third year. It is directly responsible for the loss of one student from this group who commented:

I'll be back next year when, hopefully, the course will not discriminate against students who cannot make timely contributions to discussions (or the University pays my mortgage so I can give it priority over my employer!)

I'm off now to read a few books over the coming months just to prove to myself, at least, that it is possible to learn without discussion.

Most students who joined in the first year of the course are of necessity autonomous learners, as any who were not have already left. For such learners it may seem an unnecessary imposition to require them to be involved in a collaborative learning process. It is also possible that insufficient attention has been paid to the significant benefits of peripheral involvement or 'lurking', which might still enable learners to enjoy the benefits of internalized dialogue. Preece suggests that this kind of involvement may be highly immersive, leading to strong senses of belonging to the community despite lack of direct interaction (Preece, 2000, pp. 87-90).

\section{Conclusion}

The evolution of this course continues and this paper is just a snapshot capturing its progress so far from the authors' highly situated perspective. There are few immutable conclusions to be drawn from the experiences presented here, but several issues seem worth emphasizing.

Firstly, the struggle for predominance between dialogue and structure has shifted throughout the course's short life and shows no signs of abating, despite well-intentioned efforts to force it in a particular direction. This lends credence to Moore's theory of transactional distance: as structure increases, dialogue decreases and vice versa.

Secondly, it is difficult to implement something new when surrounded by selforganizing forces that tend towards equilibrium and reinforcement of the status quo.

Though by no means original, the following conclusions also bear repeating.

Firstly, the transition from face-to-face teaching to online learning requires a realistic (and large) allocation of resources. High structure requires a lot of up-front investment (Laurillard, 1993), whereas high dialogue needs this to be ongoing. 
Secondly, transforming teaching practice in the radical way required to implement a successful online course requires a thorough but sensitive approach to educating tutors as well as students.

Thirdly, in the absence of tacit social cues, weaknesses in pedagogy are accentuated in an online environment. Those social cues are significant: 'Efficient communication relies not on how much can be said, but on how much can be unsaid' (Seely Brown \& Duguid, 2000). To help overcome this, the authors believe that pedagogic theories should be explicitly applied as part of the strategic underpinning of a course.

Finally, maintaining regular face-to-face contact throughout the module encourages avoidance of online discussion. An alternative approach, using concentrated face-to-face periods at greater intervals, is currently being considered.

Despite the setbacks, the authors still believe in the importance of the principal strategy of building a successful learning community. If our aim is to produce independent, thinking and questioning graduates, we must be prepared to cultivate and nurture a collaborative online community in which geographical distance becomes less relevant as transactional distance shrinks.

This paper has largely dwelt on the things that have gone wrong. It has made little mention of the fact that those students who remain are highly effective learners, achieving high commendations from internal and external examiners alike. It has said little of the tutors' extraordinary dedication and care for students, nor of their high levels of skill and expertise that have been brought to bear on the course, nor the close-knit teams that make it all possible.

The complex system that we recognize as a course is made of the interactions of its own parts and with other systems, including those of which it is a constituent. Like many complex systems, it learns and develops with an internal dynamic very different from the sum of its components, not always in the ways that its leaders expect or intend. The movement from structure to dialogue and back again is one that can be strongly influenced, but seldom fully controlled. That control arises at least in part from the systemic interactions within the system itself.

Despite the inadequate recruitment, the high student drop-out rate, the rapid staff turnover, the unplanned disasters and the unintentional consequences of intentional change, the eSystems course is in many ways a successful system. It has strong internal cohesion, yet it is fuelled by diversity. In adversity it has displayed an adaptive dynamic and continues to evolve, despite as much as because of those who try to control it.

\section{References}

Bruner, J.S. (1966) Toward a theory of instruction (Cambridge, MA, The Belknap Press of Harvard University Press).

Brusilovsky, P. (2001) Adaptive hypermedia, User Modeling and User Adapted Interaction, 11(10), 87-110.

Dron, J. (2004) Termites in the schoolhouse: stigmergy and transactional distance in an e-learning environment, paper presented to Edmedia 2004 (forthcoming), Lugano, Switzerland.

Gagne, R. (1985) The conditions of learning (4th edn) (New York, Holt, Rhinehart \& Winston). 
Garrison, R. (2000) Theoretical challenges for distance education in the 21 st century: a shift from structural to transactional issues, International Review of Research in Open and Distance Learning, 1(1), 1-17.

Holt, J. (1977) Instead of education: ways to help people do things better (Harmondsworth, Penguin).

Illich, I. (1971) Deschooling society (New York, Harper \& Row)

Kolb, D. A. (1984) Experiential learning (Englewood Cliffs, NJ, Prentice Hall).

Laurillard, D. (1993) Rethinking university teaching- a framework for the effective use of educational technology (London, Routledge).

Moore, M. G. \& Kearsley, G. (1996) Distance education: a systems view (Belmont, Wadsworth).

Peters, O. (2000) The transformation of the university into an institution of independent learning, in: T. Evans \& D. Nation (Eds) Reflections on creating educational technologies (London, Kogan Page), $10-23$.

Preece, J. (2000) Online communities: designing usability, supporting sociability (Chichester, Wiley).

Saba, F. \& Shearer, R. L. (1994) Verifying key theoretical concepts in a dynamic model of distance education, The American fournal of Distance Education, 8(1), 36-59.

Salmon, G. (2000) E-moderating: the key to teaching and learning online (London, Kogan Page).

Seely Brown, J. \& Duguid, P. (2000) The social life of information (Boston, MA, Harvard Business School Press).

Senge, P. M. (1993) The fifth discipline - the art and practice of the learning organisation (Chatham, Century Business).

Vaill, P. (1996) Learning as a way of being: strategies for survival in a world of permanent white water (San Francisco, CA, Jossey-Bass).

Vygotsky, L. S. (1978) Mind in society (London, Harvard University Press).

Wedemeyer, C. A. (1971) Independent study, in: R. Deighton (Ed.) Encyclopedia of education, vol. IV (New York, Macmillan), 548-557.

Wenger, E. (1998) Communities of practice: learning, meaning and identity (New York, Cambridge University Press).

Whitehead, A. N. (1929) The aims of education and other essays (New York, The Free Press). 